\title{
Monitoring the Wadden Sea - an introduction
}

\author{
Karsten Reise \\ Biologische Anstalt Helgoland, Wadden Sea Institute Sylt; D-2282 List, FRG
}

\begin{abstract}
The Wadden Sea is an ecotone of far-reaching importance. Its nature is continuously changing, and ecological monitoring is needed to identify and analyse trends, and to inform the general public about accelerated change caused by human impact. Sustained ecological research with a diversified monitoring program is essential to overcome the 'immature phase' of short-term and single-site studies in ecological science. Long-term and wide-scale phenomena are of increasing relevance to human welfare. Ecological monitoring includes retrospective and ongoing recordings of physical, chemical and biological parameters on a regional scale. It improves our understanding of natural patterns and processes, and of the distortions caused by man. It may provide early warnings. It is a necessary precondition for translating the principle of anticipatory action into practical policy. and it also documents the effects of actions taken. Monitoring the Wadden Sea will help to protect its great variety of flora and fauna, and will also prevent it from deteriorating into a gray coastal backwater, serving for utility purposes only.
\end{abstract}

\section{INTRODUCTION}

Current ecological science is dominated by snapshot observations and short-term experiments, promising quick rewards for the bright scientist. Under the tacit assumption of stable systems kept in equilibrium by cybernetic feedbacks, ecologists have for far too long aped the methodology of classical physics. However, the living world is different. Ecology should be devoted to the diversity of life in the real world, and we should not long for the shining clarity of the abstract phenomena designed by the human mind.

The acceleration of change in the real world, in society, technology and environment, has led many to seek compensation in the dream of an unchangeable nature. Nothing could be more unrealistic. Nature has been continuously transforming since its very beginning, and will keep on changing long after the last human has turned into a fossil.

The older we become, the more we perceive change in and around us and acknowledge the importance of history. The more we travel, the greater the sense of proportion we have for the quality of our immediate environment. In a similar way, the science of ecology has come of age and advanced to global perspectives.

Accordingly, it is now recognized that monitoring changing patterns is the basis for an improved understanding of nature. Retrospective studies are a prerequisite to understanding the present processes. In addition, monitoring provides us with the necessary feedback concerning human impact on the environment. 


\section{NOISES IN AN ECOTONE}

Monitoring is a part of research, and without it meteorology, hydrography and ecology would miss their most decisive phenomena. In the sea, short-term variability of physical factors is damped out by the large heat capacity of the oceans (Steele, 1985). This leads to relatively large-amplitude changes at long time scales. As a consequence, the variance of physical factors gradually increases as the time interval increases from days to decades. This environmental characteristic of the sea has been termed 'red noise' by analogy to the red light spectrum. Models suggest that this 'red noise' may cause abrupt changes in the biota, while the physical change remains gradual.

In the tidal zone of the Wadden Sea, the 'red noise' turns into 'white noise'. Environmental variability increases towards high tide line, but this variance appears to be constant as the time interval increases from very short to up to about 100 years.

In the Wadden Sea we have a mixture of red and white noises: a high short-term variability superimposed on slow changes with long periodicities. Thus, monitoring physical, chemical and biological parameters in this ecotone between the land and the sea, and differentiating between natural and man-made change, is quite a challenging endeavour. On the other hand, the very fact that the Wadden Sea is an ecotone with transregional connections means that it is a sensitive indicator of processes going on in a wider field.

\section{LONG AND WIDE SCALES}

Only when monitoring proceeds from the scale of years to decades may we hope to detect long-term trends, possibly recognize subtle effects revealed under the stress of rare episodes, and account for biotic time lags in response to a disturbance. In the Wadden Sea around Sylt, sea urchins (Psammechinus miliaris) and slipper limpets (Crepidula fornicata) were strongly decimated by the severe winter 1978/79. First signs of recovery became apparent not earlier than 10 years later. Furthermore, it remains an open question as to why these two species suffered so severely in the winter 1978/79 but not so during the colder winter of $1962 / 63$. There might have been a weakening of the population due to some hidden factor prior to the winter of $1978 / 79$.

Enhanced growth of green algae in the Wadden Sea has been observed since the 1970 s, and this seems to be in response to an increased nutrient supply. The first largescale mass development occurred in the East Frisian Wadden Sea during the unusually warm and sunny summer of 1989. Presumably, it was the rare coincidence of nutrient load and prolonged sunshine which triggered the green algae to cover wide areas of formerly unvegetated tidal flats. Future monitoring will show whether these algae, once established, also persist under less favourable conditions.

Monitoring requires not only long-term observations, but also the adoption of a widescale approach. Spatial uniformity is an exception in nature. Instead, dynamic mosaics prevail in ecosystems (Remmert, 1985). Mosaic elements of various sizes tend to undergo cyclic or erratic successions. Depending on the history of disturbances and the type of colonizers, each mosaic element adopts its own shape, speed of change and course of development. Attempts to identify overall trends and events in such ecosystems necessitates a mapping approach. Isolated sampling stations are of little value.

A proper monitoring design must be developed towards the diagonal in the space- 


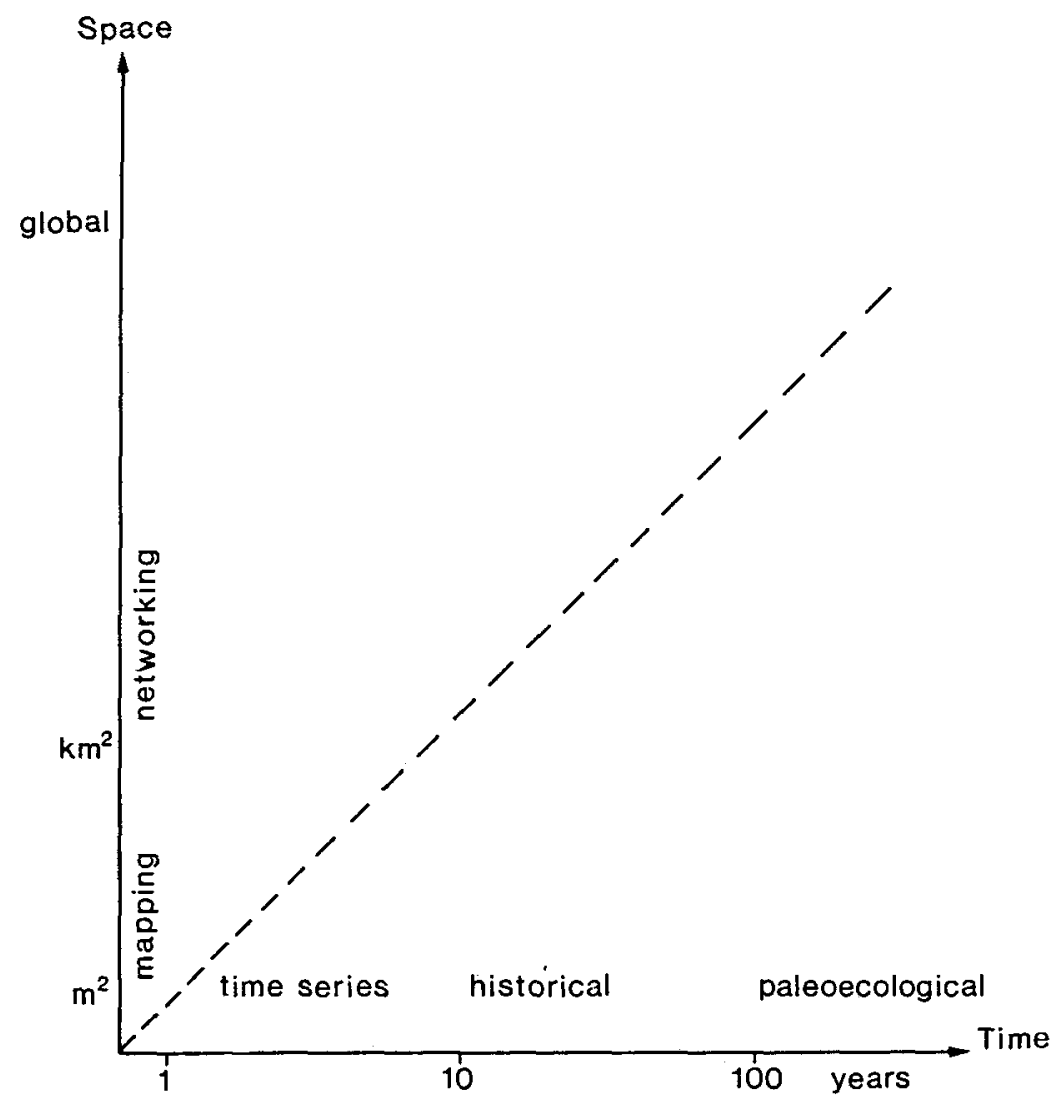

Fig. 1. Spatial and temporal scales of ecological monitoring. The time scale includes retrospective studies. Monitoring strategies should proceed along the diagonal

time diagram (Fig. 1). An actual compromise must be arrived at in relation to the problem under investigation, and in relation to adequate costs (de Wolf, 1989).

\section{ECOSYSTEM APPROACH}

Sustained ecological research, monitoring being a part of this, must be concerned with the cascading effects of climatic and sea-level changes, with the long-term and wide-scale effects of exploitation and nature management, with pollution and species introductions. More questions can be answered not only with an increasing scale of observation, but also by recording these variables at the same time and at the same sites. Otherwise, interactions which often determine the observable pattern are missed. They are also missed when recording is not combined with causal research. All this is only feasible with an ecosystem approach (Likens, 1989).

Long-term ecosystem research should be initiated in selected areas, where historical comparisons and paleological analyses provide interpretations of the present state, where 
institutes are able to guarantee uninterrupted time series studies into the next decades, and where laws defend the study area from destruction, i.e. in national parks or biosphere reserves.

Between such special research areas, a network of stations should be maintained, where monitoring according to a KISS-strategy (Keep-it-simple-and-safe) provides the intervening data and may recognize local problems. A geographical information system has to be developed which not only collects and redistributes data, but which also combines and analyses spatial and temporal trends in the light of specific questions.

A monitoring program of this kind not only improves our understanding of nature and its responses to human impact, but also may serve as an early warning system, be a basis for precautionary action, and provide a feedback when actions have been taken (Clarke, 1986).

\section{CONCLUSIONS}

Although there are a few valuable time-series studies already conducted and integrated within the framework of COST-647 (i.e. Beukema \& Essink 1986), there is still a 'laissez-faire' attitude among scientists and administrators towards long-term and widescale monitoring. This needs to be changed. Scientists must turn their attention from the day-to-year processes to the decade-to-century processes, while administrators must design the institutional and funding structures to encourage such research. The rationale behind ecological monitoring is the higher relevance of the longer term processes to human welfare. The protection of the Wadden Sea is doomed to failure without sustained ecological research with a comprehensive monitoring strategy.

\section{LITERATURE CITED}

Beukema, J. J. \& Essink, K., 1986. Common patterns in the fluctuations of macrozoobenthic species living at different places on tidal flats in the Wadden Sea. - Hydrobiologia 142, 199-207.

Clarke, R., 1986. The handbook of ecological monitoring. Clarendon Press, Oxford, 298 pp.

Likens, G. E., 1989. Long-term studies in ecology. Springer, New York, 214 pp.

Remmert, H., 1985. Was geschieht im Klimax-Stadium? - Naturwissenschaften 72, 505-512.

Steele, J. H., 198.5. A comparison of terrestrial and marine ecological systems. - Nature, Lond. 313. 355-358.

Wolf, P. de, 1989. The price of patchiness. - Helgoländer Meeresunters. 43, 263-273. 